\title{
OBSERVATORIO ANDALUZ DE ASTRONOMÍA
}

\author{
F. Espartero ${ }^{1,2}$, G. Martínez ${ }^{2}$, and M. Frías ${ }^{1,3}$
}

\begin{abstract}
The Andalusian Astronomy Observatory (OAA) has been designed and built in order to fill a gap between the professional observatory, for exclusive use for research, and the small amateur observatory. The OAA is intended to be a mid-level observatory that allows to work in Astrophysics Research and, at the same time, perform an important role in the outreach and dissemination of astronomy.

In addition to meeting the demands of the general public through exhibitions, public observations and outreach activities, this observatory is a pioneer in complying with the legal regulations that allow public access to meet the growing demand for astronomical tourism, which is also a source of additional funding for research projects.
\end{abstract}

\section{RESUMEN}

El Observatorio Andaluz de Astronomía (OAA), se ha diseñado y construido con el objetivo de cubrir un hueco entre el observatorio profesional, de uso exclusivo para la investigación y el pequeño observatorio amateur. El OAA pretende ser un observatorio de nivel medio, que permita trabajar en investigación astrofísica y al mismo tiempo, realizar una importante labor de divulgación y difusión de la astronomía.

Además de atender las demandas del público en general, mediante exposiciones, observaciones públicas y actividades divulgativas, este observatorio es pionero en cumplir con la normativa legal que permite el acceso de público, para atender la creciente demanda del turismo astronómico, lo que permite también, conseguir una fuente de financiación adicional para los proyectos de investigación.

Key Words: telescopes

\section{INTRODUCTION}

The OAA project began in 2011, with a major campaign to study the atmospheric conditions and quality of sky brightness to determine its best location, within the municipalities of Alcalá la Real, Castillo de Locubín, Frailes and Noalejo. The information obtained from amateur meteorological stations and AEMAT, in addition to the rigorous study of the sky brightness, which was carried out with a Sky Quality Meter (SQM) provided by the Department of Astrophysics and Atmospheric Sciences of the Universidad Complutense de Madrid project NIX-NOX), made it possible to determine the best areas to locate the Observatory (Figure 1).

The data provided during two years of work (2011-12) and the field measurements were also the basis for obtaining the Starlight Certification and Starlight Tourist Destination awarded by the Starlight Foundation to the Sierra Sur de Jaén,

\footnotetext{
${ }^{1}$ Observatorio Andaluz de Astronomía, 23688 La Pedriza, Alcalá la Real, Jaén, Spain (espartero@astroalcala.es).

${ }^{2}$ Departamento de Ingeniería de la Construcción y Proyectos de Ingeniería. Campus de Fuentenueva, Universidad de Granada, 18071 Granada, Spain.

${ }^{3}$ School of Physics, University of Bristol, BS8 1 TL Bristol, United Kingdom.
}

where the municipalities mentioned above are included, with the exception of Noalejo. The final result of achieving this prestigious certification of sky quality was the main trigger for building the OAA. As a result of this work and the Certifications granted, the City Council of Alcalá la Real, agreed to transfer an old abandoned nursery, reform it and adapt it appropriately to install an Astronomical Observatory for scientific, tourist and informative purposes (Espartero 2013).

\section{SITE SELECTION (SITE-TESTING)}

The methodology to be followed to correctly locate the OAA has been based mainly on studying the atmospheric phenomena that affect the radiation emitted by the objects that are intended to be observed (Varela et al., 2002), in addition to other relevant geopolitical factors, that significantly affect the choice of place. The main ones are listed below.

\subsection{Atmospheric and Meteorological Conditions}

-Atmospheric transparency

The chemical composition of our atmosphere blocks at ground level most of the electromagnetic radiation we receive from the outside, but there are so-called "atmospheric windows" that allow access 

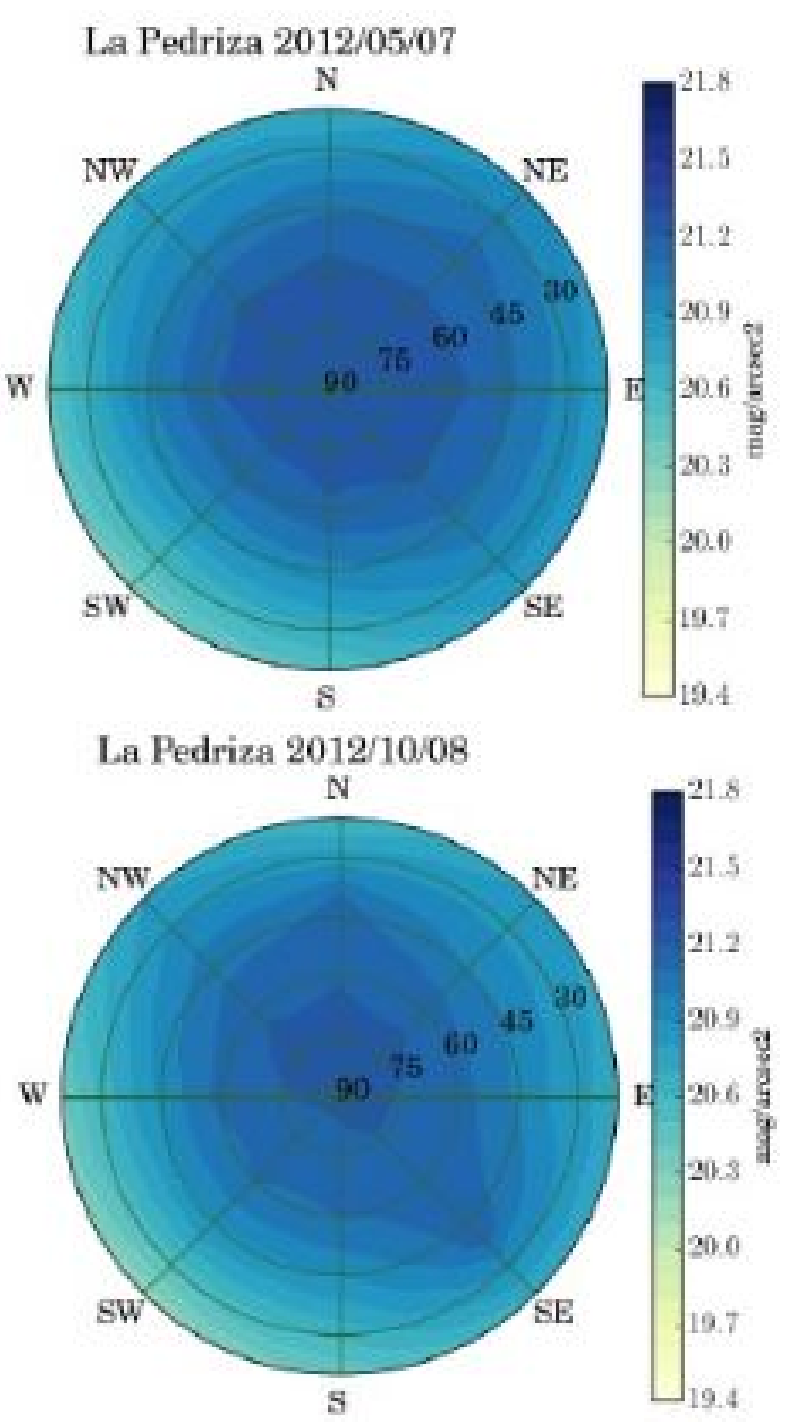

Fig. 1. Sky brightness graphs (mag/ $\left.\operatorname{arcseg}^{2}\right)$ obtained with SQM during 2012, at the location where the OAA was later located.

to certain wavelengths within the visible, radio and near infrared spectrum from a considerable height.

-Atmospheric turbulence

Due to the instability of our atmosphere the objects we observe have some distortion that do not allow them to be seen as point objects. This phenomenon occurs with different intensity according to the place of observation and it is possible to differentiate between scintillation (blink of the stars) and seeing (diffuse disk around the observed object).

-Atmospheric extinction

Phenomenon related to the height of the stars in the horizon, so that when they are low on the sky, the "absorption" and dispersion of the photons by the molecules and particles of the atmosphere becomes more intense. This affects in a very important way the observation of any object. If we also take into account the influence of aerosols, dust and the absorption produced by water vapor and other molecules such as $\mathrm{O}_{2}, \mathrm{~N}_{2}, \mathrm{O}_{3}$, we are considering Rayleight scattering.

-Atmospheric refraction

In this case we can "apparently" observe that objects appear higher on the horizon than they actually are, so that the stars slow down their movement when rising or setting, and large objects such as the sun and the moon, present an abnormal flattening.

-Light pollution

Key factor to be taken into account and very difficult to solve. The light emitted to the sky by artificial light sources causes the emitted photons to be reflected in the different constituents of the atmosphere, so that the reflected light can be greater than that coming from the majority of the stars.

-Meteorology and climate

Data from the last years regarding rain, cloudiness, relative humidity, temperature and wind speed has been studied, in addition to considering the main characteristics of the continental Mediterranean climate, typical of the considered enclaves.

-Sky Brightness

Fundamental factor to consider when selecting a good location for observations. The measurements were made with an approved photometer, which allowed to date the excellent quality of sky of the place. At present the photometer used in the OAA (calibrated and tested), shows even better data than in the period 2011 to 2012 . After building the observatory, a municipal program was launched to improve the nearby illumination to the observatory, so that unnecessary lights were removed and led luminaires with a color temperature range not exceeding 3000 $\mathrm{K}$ are now used.

-Direction and height

The height of $1030 \mathrm{~m}$ allows the observatory to have clear practicing horizon (only about $10^{\circ}$ to the West are lost), which has allowed the South to be completely clear. A good East-West-South orientation is very important, especially when considering the ecliptic and low-altitude objects that are visible to the South only some days of the year.

\subsection{Geopolitical Factors}

-Accessibility

It must have a good access road and proximity to some population center.

-Logistics and facilities 
It is important to have electrical connection, water, sanitation and other additional services such as telephone coverage and Internet.

-Support and institutional financing

The assistance of some public (or private) institutions is fundamental to finance a research project and the maintenance of the facilities.

The sum of all these factors and their exhaustive analysis led to the decision to place the OAA in the village of La Pedriza in the municipality of Alcalá la Real, at $03^{\circ} 57^{\prime} 12^{\prime \prime} \mathrm{W}, 37^{\circ} 24^{\prime} 53^{\prime \prime} \mathrm{N}$ at 1030 metres above sea level.

\section{CONSTRUCTION}

The observatory's design solution was based on having a visitor center, conditioned to accommodate between 50 and 60 people, as well as a specific module to place a 24 " telescope for exclusive research use (Organero et al., 2012).

The visitor center has a large audiovisual room, with toilets, bedroom and office configured for computer equipment (data control center). The attached construction to house the main telescope was designed to ensure maximum independence between the structure of the telescope and the rest of the building that houses it. Thus, it was decided to provide the central pillar (pillar of the telescope) with an independent structure, with an insulated basement that allows the pillar to avoid any type of perimeter vibration that would affect the telescope. The foundation slab of the rest of this building was insulated by means of poliexpan plates to avoid contact and any kind of disturbance around it (Figure 2). This premise was also considered in the forging of the first floor and in the rest of the building accessories, such as the metallic access staircase, anchored (with polyurethane sinenblocks) in the foundation slab, and the dome support rings, which rest on the first slab.

The observatory module is built on a square section base of 4.2 meters on the side with double concrete blocks on a foundation made of reinforced concrete. The forge is arranged with prestressed beams of $4.20 \mathrm{~m}$ in length and $180 \mathrm{~mm}$ of core, poliexpan vaults, reinforced perimeter band, grating and compressive layer of concrete HA-250.

The interior finish in rustic flooring of $33 \times 33 \mathrm{~cm}$ stands out on the finish of the walls, with a double layer of white marmolina. We must only add the facilities for electricity and data to this functional finish, which have been buried to connect with the visitor center and the control and data room. Two aerators (East and West walls) that allow ventila-

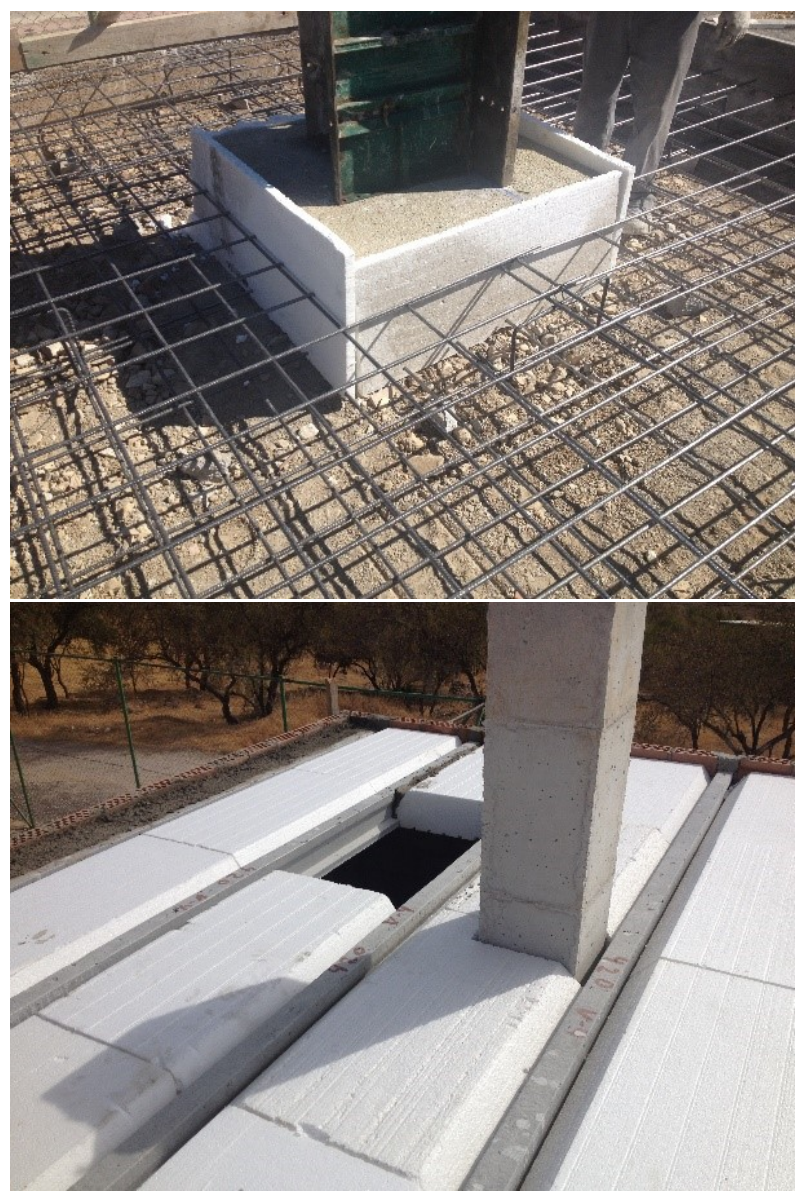

Fig. 2. Detail of the foundation of the pillar and structure. It can be seen how the pillar and its foundation slab are totally isolated from the rest of the structure of the building.

tion and thermal exchange of indoor-outdoor temperature are also included. This is an important element as it helps the telescope's optics not to undergo sudden temperature changes when it starts a work session.

The OAA has been built for a perfect South orientation. In this way it has been possible to construct a sundial oriented towards the South and at the moment we are planning on placing two more on the sides of the building with East and West orientation (Figure 3).

\section{EQUIPMENT}

The OAA currently has the following telescopes and additional material:

- Ritchey-Chrétien TS $406 \mathrm{~mm}$ with f/5 focal length on Paramount ME II German equatorial mount. 


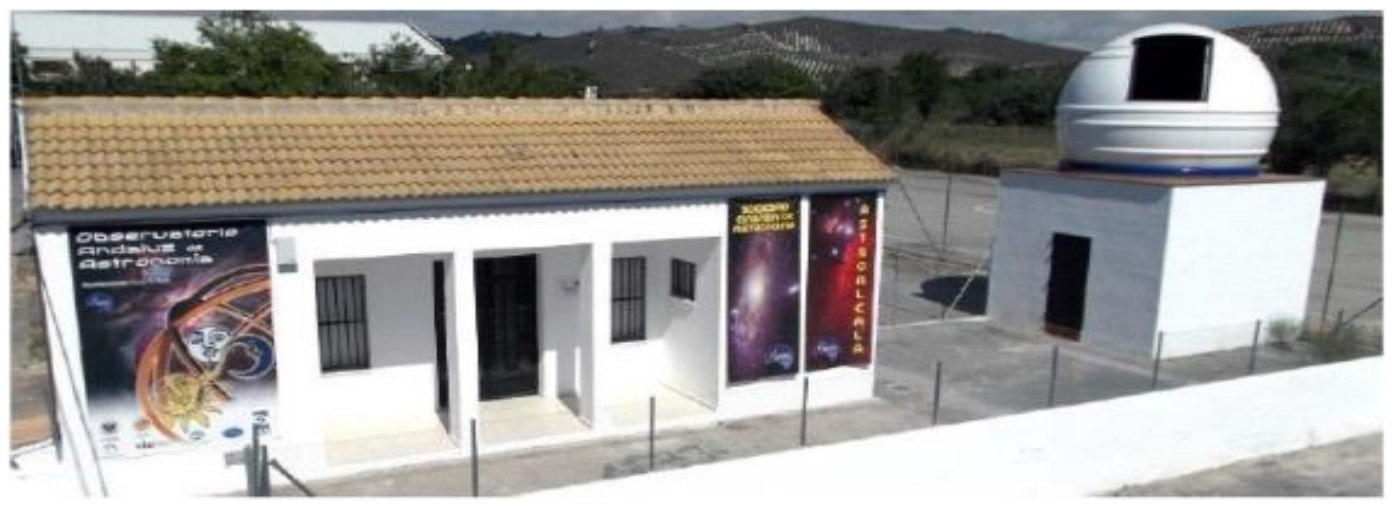

Fig. 3. Eastern view of the OAA main entrance.

- Schmitdt-Cassegrain Meade LX200-ACF GPS $304.8 \mathrm{~mm}$ with $\mathrm{f} / 10$ focal length on equatorial fork mount.

- Newton 8" with f/8 focal length on Meade LX75 German equatorial mount.

- Refractor 6" with f/5 focal length on Meade LX75 German equatorial mount.

- Newton-Dobson 24" with search and tracking system PicGOTO ++.

- LUNT 60 mm Solar Telescope.

- Atik $314 \mathrm{~L}+$ and Atik 1100 CCD's.

- 2" (7) filter wheel and 2" SBIG filter.

- Lodestar guided and planetary CCD.

In addition to these equipments, two spectrographs and three video cameras are available to detect and analyze bolids and meteors, with which several research projects have been carried out (Espartero \& Madiedo 2016, Espartero 2017).

\section{FUTURE PLANS}

- Expand the OAA facilities by providing a new module for public observations. This project includes accessibility improvements for people with disabilities and reduced mobility. It is also planned to install led luminaires as night signaling beacons $(2700 \mathrm{~K})$ to facilitate access and mobility to visitors (Figure 4).

- Design of solar park with new sundials and a plinth of Ptolemy.

Acnowledgements: We acknowledge A. J. Castro-Tirado for fruitful conversations. We would like to thank the technical support received by the company Ingeniería ECS, SL, Cristóbal García for

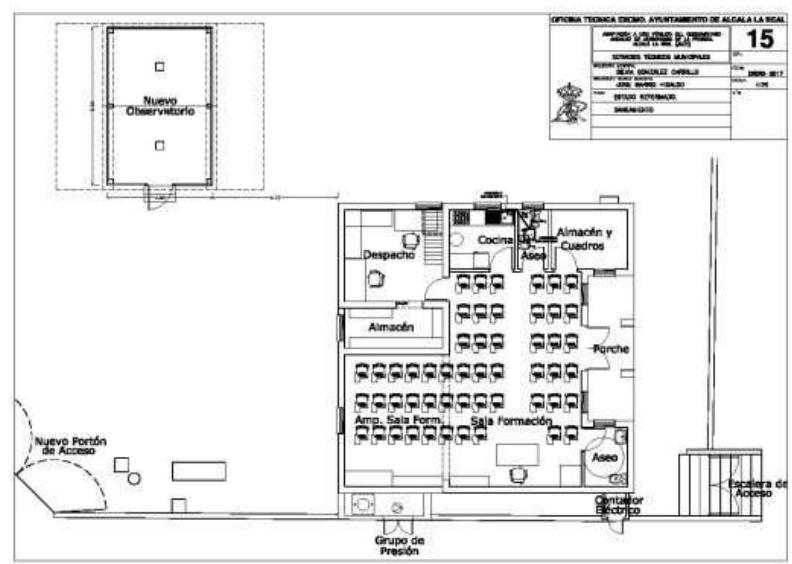

Fig. 4. One of the plans of the OAA extension project.

helping us with the meteorological astronomy station (EMA), Francisco S. Montes for his technical work and constant support throughout the OAA project, the City Council of Alcalá la Real for the funding received and the assignment of the building and the Exma. Diputación de Jaén.

\section{REFERENCES}

Espartero, F. A. 2013, TFM, Univ. Granada, Spain

Espartero, F. A. \& Madiedo, J. M. 2016, EMP, 118, 81, DOI 10.1007/s11038-016-9491-4

Espartero, F. A. 2017, PhD Thesis, Univ. Complutense Madrid, Spain

Organero, F., Hernandez, L. A., \& Fonseca, F. 2012, EPSC2012-89-01, Vol.7

Varela, A., Muñoz-Tuñon, C., \& Gurtubai, A. 2002, ASPC, 266, 336 